\title{
Viagem à América
}

\author{
[ Voyage to America
}

\section{Marcelo Maraninchi ${ }^{\mathrm{I}}$}

COSTA, Hipólito José da. Diário da minha viagem para Filadélfia. Edição crítica: Tânia Dias. Rio de Janeiro: Fundação Casa de Rui Barbosa; Belo Horizonte: Editora UFMG, 2016.

De Lisboa, em fins do século XVIII, Hipólito José da Costa parte, na corveta William, rumo aos Estados Unidos. Formado por Coimbra, em direito e ciências naturais, o jovem vai em missão oficial. Visita Filadélfia, Boston, Nova York. Tem contato com estudiosos de botânica, Bartram e Hamilton, e conhece o presidente do país, John Adams. Comparece até mesmo a um baile de aniversário do general Washington, mas, quando este morre, meses depois, não vai às exéquias - faltam-lhe trajes e crédito $^{2}$. Na América, busca dados sobre a cochonilha e as culturas do arroz, açúcar, tabaco e algodão. Sua viagem responde a interesses políticos e econômicos da Coroa: segue a diretriz administrativa colonial de modernizar o cultivo agrícola e a extração das minas. Seu olhar é pautado pelas instruções de d. Rodrigo de Sousa Coutinho e do frei José Mariano da Conceição Veloso, e pelos manuais que orientavam a prática de observação dos viajantes 3 . Nos cadernos que leva consigo, desenha para ocupar o tempo e reter imagens que lhe despertam a atenção: barcos, a torre de Belém, instrumentos de cultivo.

MARANINCHI, Marcelo. Viagem à América. Revista do Instituto de Estudos Brasileiros, Brasil, n. 65, p. 244-250, dez. 2016.

DOI: http://dx.doi.org/Io.II606/issn.23I6-90IX.voi65p244-250

I Universidade de São Paulo (USP, São Paulo, SP, Brasil).

2 "Hoje se fizeram as honras funerais ao General Washington a que eu não assisti por não ter luto nem dinheiro para comprar; porém tenho a descrição que foi publicada na Gazeta." COSTA, Hipólito José da. Diário da minha viagem para Filadélfia. Edição crítica: Tânia Dias. Rio de Janeiro: Fundação Casa de Rui Barbosa; Belo Horizonte: Editora UFMG, 20I6, p. I73.

3 A indicação de obras e autores que compõem o repertório de Hipólito José da Costa, funcionando como matrizes do Diário, é um dos méritos da introdução elaborada por Tânia Dias. 
Minucioso no relato de instituições civis e sobretudo técnicas de semeadura e colheita, no que atende à orientação de d. Rodrigo, o Diário da minha viagem para Filadélfia é composto também do registro da vida cotidiana e da colagem de trechos curtos, traduzidos de obras científicas. Cobre o período de outubro de I798 a dezembro de I799 e interessa como documento da formação do autor e do projeto de modernização da Coroa, em meio ao processo de autonomia política e constituição dos Estados do novo mundo. O Diário nos mostra, passados dois séculos, fragmentos dos primeiros tempos de um país independente e republicano, pelo ângulo de um membro da elite luso-brasileira, ainda sob o regime antigo. A diferença entre o viajante e o país onde desembarca é parte do encanto do texto, dotado de estilo espontâneo, que envolve o leitor em passagens de lirismo inesperado. $\mathrm{O}$ encontro de Hipólito José da Costa com John Adams, em Io de janeiro de I799, é ilustrativo da diferença:

Hoje fui apresentado pelo nosso Ministro ao Presidente dos Estados Unidos John Adams. Ele todas as terças-feiras faz o seu levee, e hoje era além de dia de levee dia de ano-bom que aqui celebram muito. A casa constava de uma antessala, ou sala de espera onde estavam dois criados de farda, e onde as pessoas que entravam deixavam os seus capotes (e alguns mesmo o chapéu); havia depois desta sala mais duas, uma onde estava o Presidente, e outra onde havia uma mesa com ponche, vinho, e uns bolos doces, que todas as pessoas eram obrigadas a provar segundo a etiqueta, e que alguns comiam a fartar. O Presidente estava de pé de casaca, espada, e chapéu debaixo do braço conversando com alguma das Pessoas que ali se achava; quando se entra, dirige-se a ele e se lhe faz um cumprimento ele pega na mão, pergunta pela saúde, e diz mais alguma coisa, a mim me perguntou que tal achava o seu País, depois disto, todas as pessoas conversam umas com as outras, mesmo passeiam pela casa e o mesmo Presidente muda de lugar frequentemente de modo que estão todos confundidos sem ordem ou arranjamento de etiqueta; os Senadores e pessoas mais qualificadas que entraram vinham uns de botas, outros sem pós no cabelo, casacas velhas quase todos, vieram a pé a maior parte; de sorte que à exceção dos ministros estrangeiros, todo 
o resto respirava muito pouca civilização, e maneiras polidas; à saída não se lhe fez outro cumprimento que uma vênia com a cabeça a que ele correspondeu igualmente ${ }^{4}$.

Se aqui predomina o reproche aristocrata, o Diário revela em muitas passagens o apreço do autor pela simplicidade. No baile em honra do presidente, em I6 de janeiro, transparece a mistura de desagrado e aprovação; um pouco mais favorável, apenas, à rusticidade norte-americana. Hipólito José da Costa observa que "a má disposição reinou em tudo”. Elogia, porém, o estado de espírito dos participantes e a tranquilidade com que transcorre o evento:

[...] as mesas à ceia não tinham criados para servir, não tinham pratos para se mudar; não havia facas e garfos senão de ferro; não se mudavam nem lavavam; a harmonia reinava por toda a parte, nada de descontentamento, nenhuma perturbação nem inda fora com as imensas carruagens que havia, criados, etc., se ouviu uma só bulha apesar de não haver guardas absolutamente; mas este sossego é o caráter geral da Nação; o Ministro de Portugal gozou das primeiras honras em tudo depois do Presidente. As gazetas atestam que é a maior função que aqui se tem feito; o que me dá a entender que nunca nos E.U. se viu uma função brilhante 5 .

A edição crítica do Diário, a cargo de Tânia Dias, difere das anteriores - a última foi publicada no Brasil em $2004^{6}$ - no tratamento do texto e na descrição minuciosa do manuscrito. Contém uma introdução crítico-filológica, mais a análise das razões da viagem e da linguagem descritiva usada pelo autor. A pesquisadora da Fundação Casa de Rui Barbosa sublinha a relevância da obra para a concepção de jornal desenvolvida por Hipólito José da Costa; alude à possibilidade de seu preparo modelar a prática dele, mais tarde, como editor do Correio Braziliense, e o formato assumido pelo jornal - teria inspirado, por exemplo, a seção Comércio e Arte, de temas diversos. A hipótese é desenvolvida de modo sucinto e anunciada como objeto de um trabalho futuro, sobre "a constituição de uma voz narrativa que se esboça nos escritos íntimos e oficiais e que se consolida nas páginas do Correio Braziliense entre os anos de I808 e I822”.

Para o estabelecimento do texto, Tânia Dias ancorou-se no manuscrito autógrafo - códice de 20,5 cm de altura por I6 cm de largura, escrito a tinta preta, conservado na Biblioteca Pública de Évora, em Portugal -, ocupando-se da padronização e atualização gráficas. A introdução crítico-filológica do volume explica e fundamenta em detalhe as escolhas da edição. Foram atualizados, em sua maioria, os ditongos (p. ex., pexe > peixe, pateo > pátio, chapeo > chapéu), a posição do til (razaõ > razão), a grafia de vogais (curveta > corveta, quazi > quase) e a acentuação. Em casos específicos, conservaram-se

4 Ibidem, p. 29.

5 Ibidem, p. 40.

6 COSTA, Hipólito da. Diário da minha viagem para Filadélfia: I798-I799. Brasília: Edições do Senado Federal, 2004.

7 DIAS, Tânia. A escrita diária de uma “viagem de instrução". In: COSTA, Hipólito José. Diário da minha viagem para Filadélfia. Edição crítica: Tânia Dias. Rio de Janeiro: Fundação Casa de Rui Barbosa; Belo Horizonte: Editora UFMG, 20I6p. XXIX. 
variantes dicionarizadas (tais como doirado e desembarcadoiro). Palavras em inglês e nomes próprios, quando grafados em desacordo com a regra atual, e outros termos ou construções interpretados como deslize foram corrigidos. $\mathrm{O}$ apóstrofo indicador de elisão (d'oiro, d'arma, mão d'obra), neologismos (farinoso, barrilinho, asserpentinadas), inclusive os de origem francófona (plesanteria) e anglófona (New Amsterdão, café house), assim como a concordância e a sintaxe seguiram a lição do autor.

Além da escrita inventiva, o Diário apresenta uma pontuação "particularíssima", consistentemente abordada pela organizadora no texto introdutório. Os casos de troca de pontuação no trabalho de fixação do texto são explicitados na introdução, como os dois-pontos substituídos por vírgula ou ponto e vírgula. Suprimiu-se o sinal de igualdade, empregado com frequência no manuscrito para indicar pausas e abrir parágrafo, em prol da legibilidade; conservado o sinal, o leitor talvez pudesse se ver um pouco mais próximo do trabalho sujo do manuscrito. A pesquisa cuidadosa municia o aparato crítico, no rodapé, referenciando nomes de pessoas, obras e lugares, assim como noticia variantes e aspectos de interesse genético, a exemplo de acréscimos e rasuras. Na introdução, Tânia Dias procura caracterizar o Diário como escrita em vaivém, baseando-se no manuscrito, que conserva indícios das temporalidades diversas de sua gênese.

\section{ETHOS ILUSTRADO E ESTILO DO TEXTO}

Há dois aspectos interessantes pelos quais se percebe a inclinação ilustrada de Hipólito José da Costa. Um deles diz respeito ao gosto dos experimentos científicos. Cruzando o Atlântico, aborrecido com a dificuldade de anotar com precisão o percurso do navio, o viajante cria um método novo: "O trabalho que me dava o fazer a derrota calculada pelas tabuadinhas me fez imaginar um método mais fácil, por meio de um instrumento que inventei, e que pretendo mandar fazer de latão logo que chegar a Filadélfia"8. Nos Estados Unidos, interessa-se pelo tempo de duração da água até se corromper: "Hoje pelas Io horas enchia uma garrafa de água da bomba para experimentar quanto tempo dura até se corromper; e vou assentando o estado da atmosfera pelo termômetro de Fahrenheit". Também a relação do autor com a cultura escrita é digna de nota. A bordo da corveta, recomenda a um soldado suíço que deseja regressar à Saxônia que tome um navio hamburguês. A ideia não agrada ao outro: "a razão que me deu foi que em tais Navios costumavam fechar os homens no porão e mandá-los violentamente para a Índia”. A princípio Hipólito não crê na justificativa do soldado. Seu caso, digamos, é de ler para crer: "Não lhe dei muito crédito mas lendo hoje as viagens do Dr. Thunberg lá achei este costume praticado na Holanda, e diz mais: que em Amsterdã há malvados que vivem de furtar homens

8 Ibidem, p. 5 .

9 Segue: “Um sujeito me disse que no tempo de verão tinha deixado um copo d'água descoberto sobre um cemitério desta cidade por uma noite; ao outro dia tinha evaporado uma terça parte e o resto tinha a consistência de geleia mole com um grande sedimento de cor amarelha, e fétida”. Ibidem, p. 4I. 
chamados kidnappers" ${ }^{\text {тo }}$. O curioso é que, logo na sequência, a palavra escrita seja duplamente desmentida pela experiência. A tábua de mantimentos dos marinheiros, afixada no navio, prevê o menu para cada dia da semana: carne de porco e ervilhas aos domingos; às segundas, feijão e batatas; às terças, carne de porco e feijão. Ao lado, no manuscrito, o autor acrescenta: "Esta tábua que é em consequência de um ato do Congresso nunca foi executada a bordo do meu Navio"Ir.

O Diário, sob o ponto de vista do estilo, é bastante marcado pela oscilação de idioma. Quando trata dos colonos que vão se estabelecer no interior do país, a oscilação mostra-se ampliada: constroem "uma casa em dois dias cruzando os paus, que têm cortado em 24 horas", derrubam o mato em redor, passam a plantar trigo e milho, "e eis aqui em 4 ou 5 anos um farmer que vive muito comfortable, como eles dizem, e que se é um homem d'indústria é um membro da assembleia e um respectable citizen" ${ }^{\text {"2 }}$.

Mais ainda, o estilo do Diário da minha viagem para Filadélfia é assinalado pela transição brusca. Assim como o autor passa de imediato daquilo que reprova para o que elogia, no relato do baile em homenagem ao presidente Adams, há várias sequências de corte abrupto que produzem no leitor efeito de disparate. No dia de Natal, em Filadélfia, Hipólito José menciona o sermão na Igreja Saint Mary, católica, e a prédica noturna em uma igreja metodista. A narrativa salta, na sequência, das cerimônias ligadas ao nascimento de Cristo para o meretrício espalhado pela cidade:

Há em todas as Igrejas assentos fechados para todas as famílias que pagam por eles um tanto, por ano: esta renda com as esmolas que sempre se tiram nos meetings ou ajuntamentos das festas faz a sustentação das Igrejas e Eclesiásticos, de todas as Religiões, e mesmo dos católicos. As prostitutas em Filadélfia são tantas que inundam as ruas de noite, de modo que em se vendo na rua mulher sem homem é indefectivelmente porém as suas casas são sempre isentas de perigos, o contrário que em outras partes da Europa ${ }^{\text {I3 }}$.

Pode ser que a escrita fluente e despreocupada de olhos alheios bem como as circunstâncias materiais, dimensões do suporte e disponibilidade de tempo tenham levado ao efeito involuntário. Ou, quem sabe, o pudor de Hipólito José, que guardava os domingos, explique a desarticulação do trecho. Ao mesmo tempo em que condensa a descrição dos costumes e o pouco caso com as formalidades de estilo

Io Ibidem, p. 4 .

II Ibidem, p. 5 .

I2 Ibidem, p. II8.

I3 Ibidem, p. 26. 
ou o encadeamento lógico do relato, o excerto guarda a particularidade de transitar sem peias entre os assuntos, como em várias páginas da obra ${ }^{\mathrm{I}}$.

$\mathrm{O}$ interesse em recolher elementos para estudos futuros ${ }^{15} \mathrm{e}$ as recomendações de Veloso e Coutinho, que orientam o olhar de Hipólito José da Costa, não eliminam a notação livre, e de certo modo inútil, da experiência. A "Memória" e as cartas a d. Rodrigo de Sousa Coutinho, organizadas como Copiador e registro de cartas de ofício, além dos seis cadernos de observações e um caderno de arranjamentos, liberam o futuro editor do Correio Braziliense para esses escapes. No Diário, registra a saúde e o tédio, faz autocríticas ou promessas ${ }^{16}$, sem empregar a dicção confessional. Combina, por vezes, o registro de interesse científico com peripécias romanescas. É o caso do episódio em que, chegado a Nova York, o viajante descreve a paisagem urbana, as baterias insuficientes que a protegem, os cais e armazéns ao longo da praia, os edifícios regulares e, enfim, as ruas, "pela maior parte muito estreitas" As construções de madeira, sujeitas a incêndios frequentes, impondo a necessidade de uma defesa civil bem organizada, introduzem a anedota: "hoje pegou fogo em uma casa junto à estalagem em que Eu estava, e Eu vendo a proximidade do mal peguei na minha mala às costas, e não parei com ela senão na outra extremidade

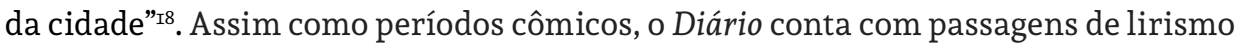
inesperado, como a comparação suscitada em New Castle, quando Hipólito José acabara de aportar nos Estados Unidos. "A névoa que tinha caído e enchia as ruas era perfeitamente semelhante ao caramelo doce que se vende em Lisboa”, ele diz.

I4 "É tal a escassez do dinheiro de oiro nos E. U. que o incômodo de levar os dollars nas viagens etc. obriga a entregá-los a um banco que dá por ele um certificado em papel, bem aceito sim em toda a parte, e pelo mesmo banco sempre que se queira outra vez a prata. $\mathrm{O}$ tabaco sendo uma mercadoria proibida em Portugal e Espanha, e sofrendo em Inglaterra muitos impostos, os Americanos exportam muito pouco, e só para a França." Ibidem, p. I2. Ou ainda: "Tendo variado muito o tempo e o vento estas 24 horas e estando o dia muito escuro se deitou a sonda mas não se achou fundo; eram 2 horas. Os Pilotos da barra em Filadélfia ganham de meter uma embarcação dentro meio guinea por cada palmo de água que demanda o vaso: por exemplo se o Navio demanda I/ palmos de água o Piloto ganha 7 guineas. Os Ingleses chamam a uma mãe d'água que cuido ser o [espaço em branco] de Lineu portuguese man-of-war (militar português)". Ibidem, p. I4.

I5 Tânia Dias apresenta o Diário como "uma escrita pessoal, de certa forma descompromissada com o registro formal, que tinha como objetivo apenas reunir observações para futuros estudos sistematizados”. DIAS, Tânia, op. cit., p. xviii.

I6 "Hoje tive notícia da Sociedade Filantrópica de Londres que por meio de subscrições particulares fez um estabelecimento de rapazes pobres para os aplicar às artes. Este estabelecimento devo Eu estabelecer no Rio Grande inda à custa de grande parte do meu patrimônio." Ibidem, p. 6.

I7 Ibidem, p. 84.

I8 Ibidem.

I9 Ibidem, p. 2I. 
MARCELO MARANINCHI é mestrando em Culturas e Identidades Brasileiras no Instituto de Estudos Brasileiros da Universidade de São Paulo (IEB/USP), sob a orientação da professora doutora Telê Porto Ancona Lopez. E-mail: marcelo.maraninchi@usp.br

\section{REFERÊNCIAS BIBLIOGRÁFICAS}

COSTA, Hipólito José da. Diário da minha viagem para Filadélfia. Edição crítica: Tânia Dias. Rio de Janeiro: Fundação Casa de Rui Barbosa; Belo Horizonte: Editora UFMG, 2016.

. Diário da minha viagem para Filadélfia: I798-I799. Brasília: Edições do Senado Federal, 2004.

DIAS, Tânia. A escrita diária de uma "viagem de instrução". In: COSTA, Hipólito José. Diário da minha viagem para Filadélfia. Edição crítica: Tânia Dias. Rio de Janeiro: Fundação Casa de Rui Barbosa; Belo Horizonte: Editora UFMG, 20I6, p. XXIX. 